\section{Case Report}

Clinical Microbiology

Ann Lab Med 2012;32:229-233

http://dx.doi.org/10.3343/alm.2012.32.3.229

ISSN 2234-3806 elSSN 2234-3814

\section{ANNALS OF LABORATORY MEDICINE}

\title{
A Case of Imported Plasmodium malariae Malaria
}

\author{
Yun Ji Hong, M.D. ${ }^{1}$, Sun Young Yang, M.T. ${ }^{2}$, Kyunghoon Lee, M.D. ${ }^{1}$, Taek Soo Kim, M.D. ${ }^{1}$, Hong Bin Kim, M.D. ${ }^{3}$, \\ Kyoung Un Park, M.D. ${ }^{1,2}$, Junghan Song, M.D. ${ }^{1,2}$, and Eui Chong Kim, M.D. ${ }^{1}$ \\ Department of Laboratory Medicine ${ }^{1}$, Seoul National University College of Medicine, Seoul; Departments of Laboratory Medicine ${ }^{2}$ and Internal Medicine ${ }^{3}$, \\ Seoul National University Bundang Hospital, Seongnam, Korea
}

Malaria, the most common vector-borne parasite infection worldwide, results from infection by Plasmodium species. Approximately $80 \%$ of malaria cases are caused by $P$. vivax, which is broadly distributed from tropical to temperate regions; $P$. falciparum is the second most common infectious species. P. malariae and $P$. ovale are responsible for a relatively small proportion of malaria cases. Here, we report the case of a 23-yr-old Korean woman who acquired a P. malariae infection while visiting the Republic of Ghana in West Africa for business. She was diagnosed with P. malariae malaria on the basis of peripheral blood smear (PBS) and species-specific conventional and real-time PCR assays for 18S rRNA. She was treated with hydroxychloroquine, and the resulting PBS examination on day 2 suggested that negative conversion occurred. At her 1-month follow-up, however, both the PBS examination and molecular test for malaria demonstrated recurrent parasitemia. We started rescue therapy with mefloquine, and the patient recovered successfully. This is an important finding suggesting possible late recrudescence of a chloroquine-resistant $P$. malariae strain identified not only by its morphological features, but also by molecular tests.

Key Words: Plasmodium malariae, Malaria, 18S rRNA real-time PCR, 18S rRNA conventional PCR, Late recrudescence, Chloroquine resistance
Received: November 21, 2011

Revision received: January 5, 2012

Accepted: February 2, 2012

Corresponding author: Kyoung Un Park Department of Laboratory Medicine, Seoul National University Bundang Hospital 166 Gumi-ro, Bundang-gu, Seongnam 463-707, Korea

Tel: +82-31-787-7692

Fax: +82-31-787-4015

E-mail: m91w95pf@snu.ac.kr (c) The Korean Society for Laboratory Medicine. This is an Open Access article distributed under the terms of the Creative Commons Attribution Non-Commercial License (http://creativecommons.org/licenses/by-nc/3.0) which permits unrestricted non-commercial use, distribution, and reproduction in any medium, provided the original work is properly cited.

\section{INTRODUCTION}

Malaria is a human infection that has been documented since ancient times. It is a vector-borne disease caused by Plasmodium species and transmitted by Anopheles mosquitoes [1]. Annually, more than 300-500 million cases of malaria are reported worldwide, and 1.5-2.7 million of these patients die from malaria infections every year [2]. In Korea, malaria cases are regularly reported. Since the re-emergence of $P$. vivax in the early 1990s, most malaria cases occurring in Korea have resulted from $P$. vivax infections. According to the Korea Centers for Disease Control and Prevention (KCDC), induced malaria comprises $1-4 \%$ of all malaria cases in Korea, in the following order of frequency: P. falciparum (41.5\%), P. vivax (36.8\%), and malaria caused by other species [3].

Many cases of $P$. malariae infections were diagnosed in Korea from the 1930s to the 1950s, and a case of co-infection with Babesia and P. malariae malaria was reported in 1998. However, these were diagnosed based only on morphologic features [4, 5]. Here, we report a case of imported malaria that was caused by P. malariae. In combination with peripheral blood smear (PBS), conventional and real-time PCR for 18S RNA were also conducted for a conclusive diagnosis.

\section{CASE REPORT}

\section{Clinical history and laboratory findings}

A previously healthy 23-yr-old woman visited the emergency room (ER) because she experienced chills for 3 days, which were exacerbated at night and were accompanied by headaches and rhinorrhea. Three weeks prior to her ER visit, she had travelled on business to the Republic of Ghana for 1 week. At the 
time of her visit to the $\mathrm{ER}$, her body temperature was $36.9^{\circ} \mathrm{C}$, and her other physical examination results were nonspecific. The laboratory tests results were as follows: hemoglobin level, $13.9 \mathrm{~g} / \mathrm{dL}$; white blood cell count, $4.4 \times 10^{9} / \mathrm{L}$ (neutrophils, $72.0 \%$; lymphocytes, 13.8\%; monocytes, 9.6\%; eosinophils, 4.4\%; and basophils, $0.2 \%$ ); platelet count, $135 \times 10^{9} / \mathrm{L}$; and C-reactive protein (CRP) level, $1.20 \mathrm{mg} / \mathrm{dL}$ (slightly above normal). Wright-Giemsa staining of the PBS was performed to screen for malarial parasites. However, the smear did not show the presence of malarial parasites. Therefore, the patient was discharged, and upper respiratory tract infection was suspected.

Six days later, she visited the outpatient clinic for follow-up and presented with diarrhea and abdominal discomfort in addition to chills. Her self-recorded body temperature was $40.3^{\circ} \mathrm{C}$. Laboratory investigations performed at that time showed that her hemoglobin level was $12.6 \mathrm{~g} / \mathrm{dL}$ and white blood cell count was $6.3 \times 10^{9} / \mathrm{L}$ (metamyelocytes, $1 \%$; segmented neutrophils, $40 \%$; lymphocytes, 42\%; monocytes, 9\%; eosinophils, 5\%; and basophils, 3\%); furthermore, her platelet count had decreased to 95 $\times 10^{9} / \mathrm{L}$, and her CRP levels had increased to $5.45 \mathrm{mg} / \mathrm{dL}$. The liver function test, which was normal at first visit to the ER, showed a slight increase in AST and ALT levels to $77 \mathrm{IU} / \mathrm{L}$ and $84 \mathrm{IU} / \mathrm{L}$, respectively. She was admitted to our medical center for further evaluation, and 3 pairs of blood culture and malaria tests (PBS and 2 different molecular tests) were performed. The blood cultures yielded negative results. The results of Wright-Giemsa staining on the PBS and the molecular tests for malaria are shown in Fig. 1 A-C (at the time of presentation), Fig. 2, and Fig. 3. She was treated with oral hydroxychloroquine (Oxiklorin; immediate dose of 800 mg, followed by 400-mg doses at 12, 24, and $36 \mathrm{hr}$ ) and was later discharged. Although malarial parasites were not observed on the PBS 2 days later and the patient was symptomfree until the next follow-up, the PBS and real-time PCR results at the 1-month follow-up showed recurrent parasitemia (Fig. 1 D-E, and Fig. 3). She was successfully treated with oral mefloquine (Lariam; immediate dose of $750 \mathrm{mg}$, followed by $500 \mathrm{mg}$ at $24 \mathrm{hr}$ ), and the results of the PBS and the molecular tests performed 7 days after completing this therapy were negative.

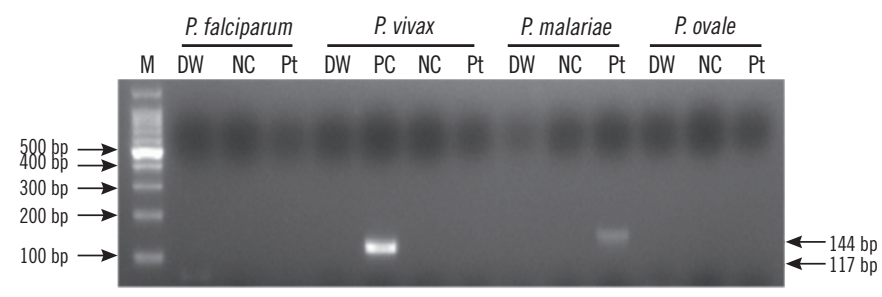

Fig. 2. Conventional PCR results for Plasmodium species-specific $18 \mathrm{~S}$ rRNA. A 144-bp fragment corresponding to $P$. malariae was detected from the PCR-amplified product of the patient's blood sample. M: DNA size marker.

Abbreviations: DW, distilled water; NC, negative control; PC, positive control; $\mathrm{Pt}$, the patient.

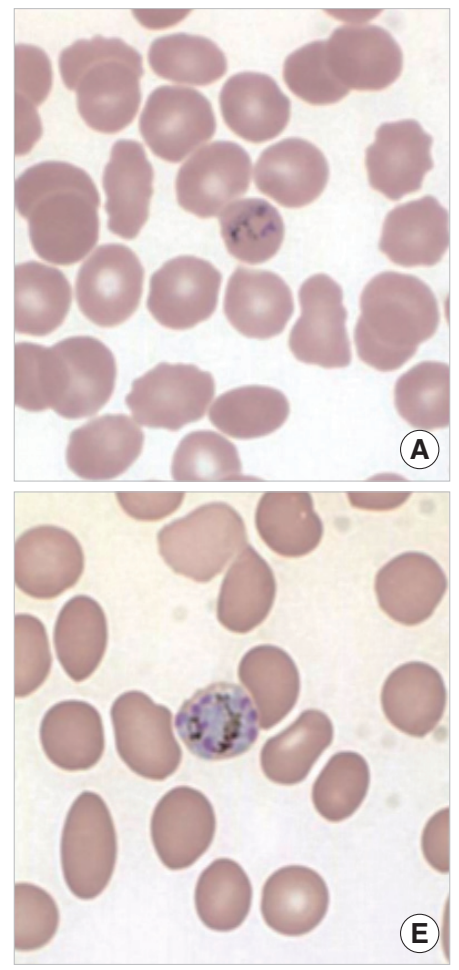

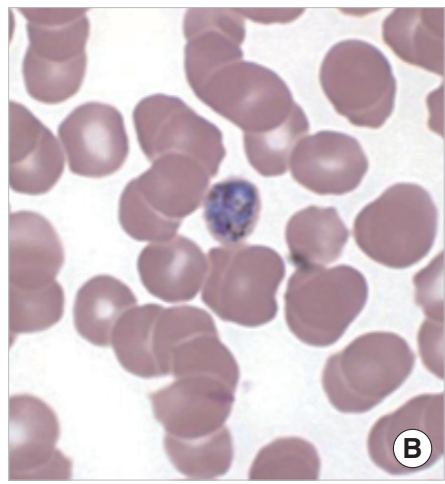
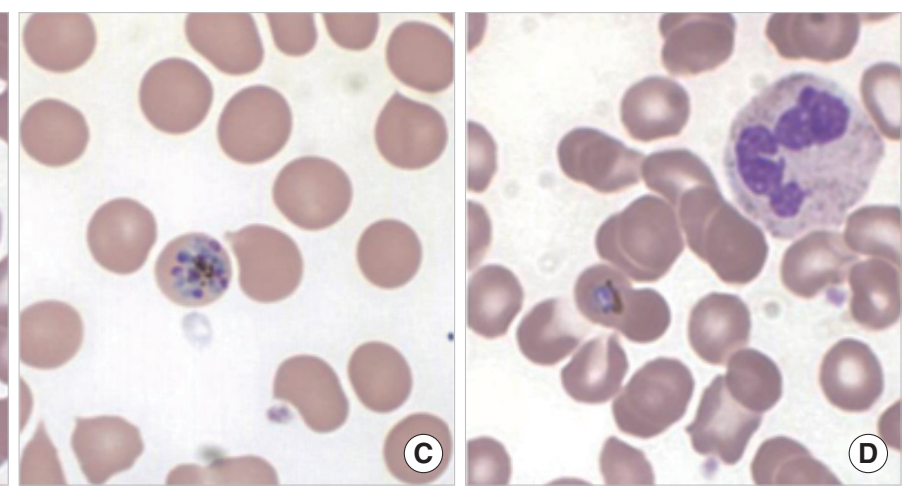

Fig. 1. Peripheral blood at the time of presentation $(A, B, C)$ and at the 1-month follow-up showing a few parasites $(D, E)$ by Wright-Giemsa staining $(\times 1,000)$. (A) Amoeboid form of a mature trophozoite; (B) an early schizont in a contracted cell; (C) a late schizont with 8 merozoites and central coarse dark pigment; (D) angular form of a mature trophozoite; (E) a late schizont with symmetrically arranged merozoites. 
Amplification Curve
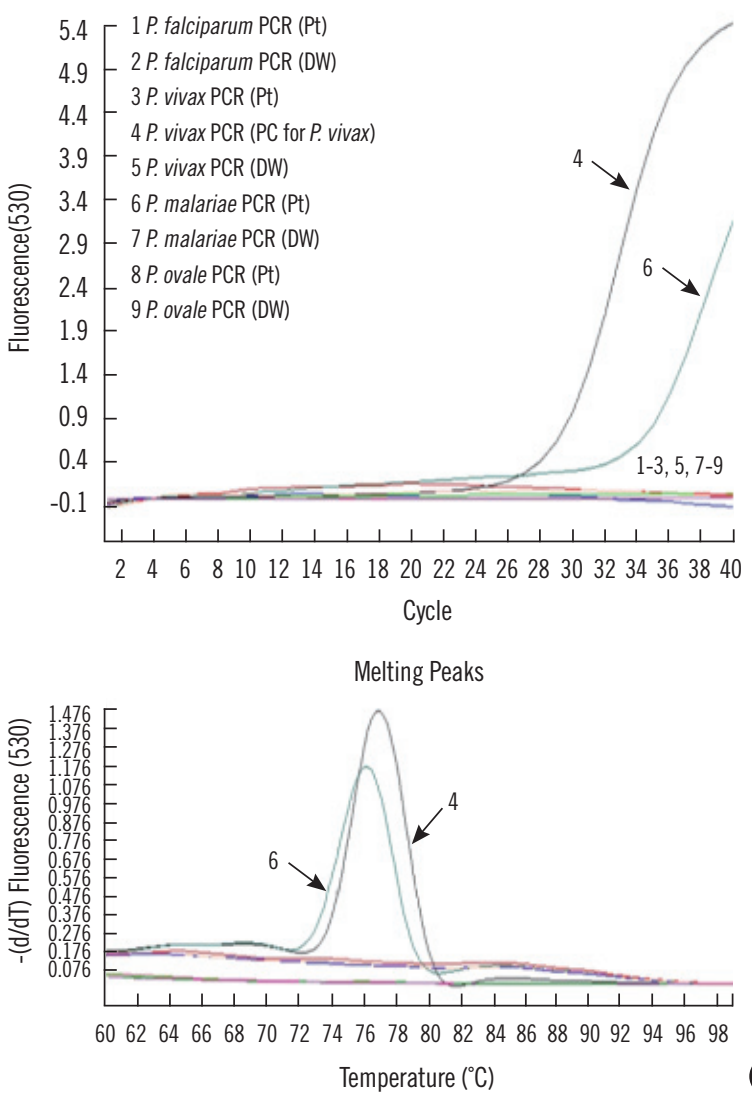

Amplification Curve
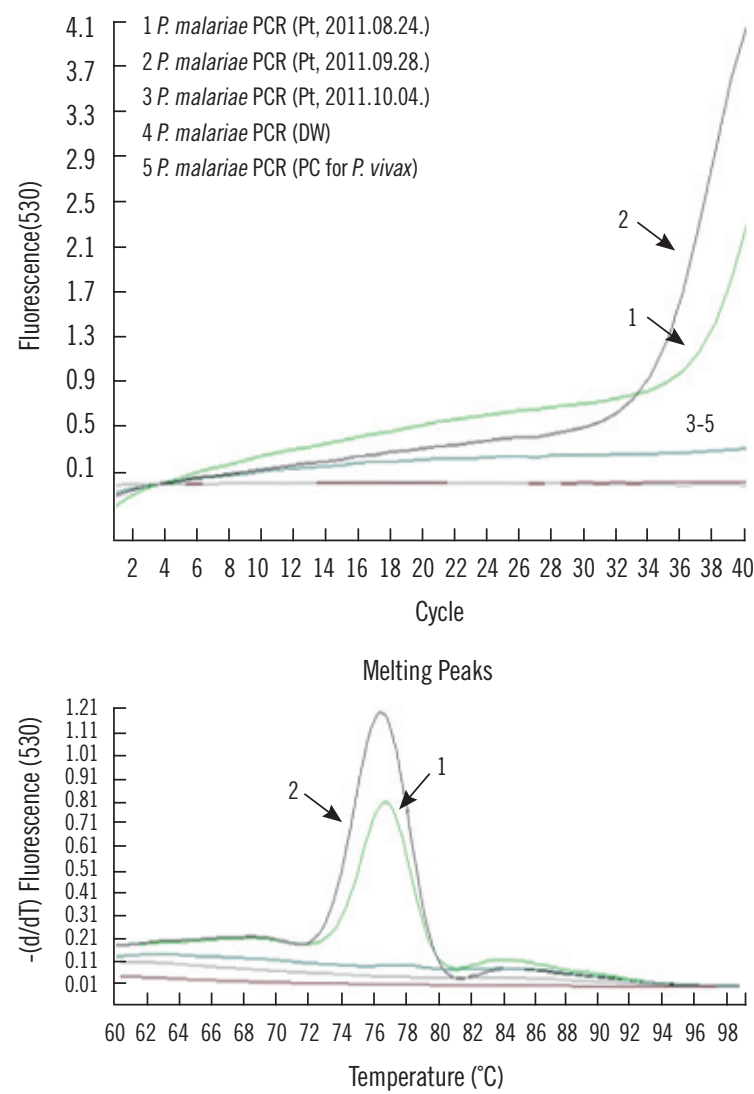

Fig. 3. Amplification plots and melting curve analyses of the 4 Plasmodium species-specific $18 \mathrm{~S}$ rRNA real-time PCR assays showing the presence of $P$. malariae. Positive results were obtained only for $P$. malariae (A). Three consecutive analyses of Plasmodium malariae-specific real-time PCR were performed, showing persistent positivity at the 1-month follow-up (2011.09.28) and then final negative conversion (2011.10.04) (B). The melting temperature $\left(T_{m}\right)$ for $P$. malariae was approximately $76.36-76.86^{\circ} \mathrm{C}$.

Abbreviations: Pt, the patient; DW, distilled water; PC, positive control.

\section{Molecular diagnosis}

For the $18 \mathrm{~S}$ rRNA, conventional PCR was performed. DNA was extracted from the blood sample of the patient using the QIAamp DNA Blood Mini Kit (Qiagen, Hilden, Germany). Four pairs of species-specific primers (rFAL1/rFAL3 for $P$. falciparum, rVIV1/ rVIV2 for P. vivax, rMAL1/rMAL2 for P. malariae, and rOVA3/ rOVA4 for $P$. ovale) that had been reported in a previous study were used $[6,7]$. Amplification was performed in a $50-\mu \mathrm{L}$ reaction mixture that contained $5 \mu \mathrm{L}$ of extracted DNA, $2 \mu \mathrm{L}$ of 10 $\mathrm{pmol} / \mathrm{\mu L}$ primer (each), $4 \mu \mathrm{L}$ of $2.5 \mathrm{mM}$ dNTP, $0.25 \mu \mathrm{L}$ of Taq polymerase (Takara, Shiga, Japan), and $5 \mu \mathrm{L}$ of $10 \times$ buffer. All the PCR cycling protocols incorporated an initial denaturation step at $95^{\circ} \mathrm{C}$ for $3 \mathrm{~min} ; 35$ amplification cycles of $95^{\circ} \mathrm{C}$ for 40 $\mathrm{sec}, 53^{\circ} \mathrm{C}$ for $1 \mathrm{~min}$, and $72^{\circ} \mathrm{C}$ for $1 \mathrm{~min}$; and a final extension step at $72^{\circ} \mathrm{C}$ for 5 min. PCR products were visualized using $2 \%$ agarose gel electrophoresis and subsequent ethidium bromide staining. Only P. malariae was detected in the patient's periph- eral blood sample (Fig. 2).

The 18S rRNA real-time PCR assays for the 4 Plasmodium species, which produce 205-bp, 117-bp, 144-bp, and 456-bp amplicons, respectively, were also performed using previously reported primers (the 4 forward species-specific primers were FWfal, FWviv, FWmal, and FWova, respectively) [8]. The components of the real-time PCR reaction mixture were as follows: 2.0 ng of DNA template with $2.0 \mu \mathrm{L}$ of LC FastStart DNA Master SYBR Green I (Roche, Penzberg, Germany), $0.4 \mu \mathrm{L}$ of each primer $(10 \mathrm{pmol} / \mu \mathrm{L})$, and $1.6 \mu \mathrm{L}$ of $25 \mathrm{mM} \mathrm{MgCl}_{2}$ in a final volume of $20.0 \mu \mathrm{L}$. The PCR program used was as follows: $94^{\circ} \mathrm{C}$ for $15 \mathrm{~min}$ and 40 cycles of $94^{\circ} \mathrm{C}$ for $5 \mathrm{sec}, 58^{\circ} \mathrm{C}$ for $5 \mathrm{sec}$, and $72^{\circ}$ $\mathrm{C}$ for $10 \mathrm{sec}$. The program for analytic melting was as follows: $95^{\circ} \mathrm{C}$ for $5 \mathrm{sec}$ and $60^{\circ} \mathrm{C}$ for $30 \mathrm{sec}$, followed by an increase in temperature to $99^{\circ} \mathrm{C}$ with a $0.2^{\circ} \mathrm{C} / \mathrm{sec}$ ramp rate. The real-time PCR assay correctly identified the presence of $P$. malariae (Fig. 3). 


\section{DISCUSSION}

Malaria is the most common parasitic disease worldwide [1]. P. vivax, $P$. falciparum, $P$. ovale, $P$. malariae, and the recently emerging $P$. knowlesi are the Plasmodium species known to cause human infections [9]. Among these species, P. vivax is responsible for $80 \%$ of all human malaria cases because of its prevalence in a wide range of areas, from tropical to temperate zones. The second most common malaria-causing species is $P$. falciparum. $P$. falciparum is limited to only tropical areas; however, it causes severe symptoms and a high mortality rate. Therefore, many countries are involved in a malaria control project sponsored by the WHO to achieve advances in malaria control [10]. The 2 species mentioned above are responsible for more than 95\% of human malaria cases, and the $\mathrm{WHO}$ eradication projects focus on these species. In contrast, the importance of $P$. malariae and $P$. ovale infections is usually overlooked.

The Republic of Ghana is located in West Africa, where the prevalence of malaria is higher than in East Africa [11]. Indeed, in Ghana, the entire nation is at the risk of malaria infection. A very large number of cases (3.7 million cases of suspected malaria and 1.9 million cases of probable or confirmed malaria) were reported in 2009 [12]. The country has been involved in the malaria control program conducted by the WHO since early 2000.

Malaria infection is suspected in patients experiencing the characteristic cyclic fever, having a history of habitation or visit to an endemic area, and presenting with other conditions, such as transfusion history. Details of the medical examination can help identify malaria to the species level. The average incubation time, for example, is influenced by the species of Plasmodium and may provide information about the source of infection. The incubation time for $P$. falciparum infections is 9-14 days, while $P$. vivax has an incubation time of 12-17 days and $P$. malariae has an incubation time of 18-40 days, which is considered relatively long [13]. In this case, although the exact time of exposure was unknown, the supposed incubation time based on travel history was 14-21 days. This information assisted partially in excluding $P$. falciparum infection.

Among the various diagnostic approaches, the common choice of method for diagnosis is microscopic examination of blood films and confirmation of parasites. Although a physician can check for the presence of parasites and other parameters through a PBS, low parasite burdens are difficult to observe on a PBS [14]. In particular, P. malariae malaria is usually chronic and asymptomatic and exhibits a relatively low parasitic load, usually less than 5,000 parasites/ $\mu \mathrm{L}$ of blood [15]. Furthermore, in $P$. ovale and $P$. malariae infections, if the infected red blood cells are damaged and their distinguishing morphologic features, such as fimbriated margins or contracted cells, are distorted, the diagnosis is more difficult [16]. Moreover, P. knowlesi, a newly discovered human plasmodia species, is similar in morphology to $P$. falciparum and $P$. malariae, according to its blood stage [17]. Therefore, in the diagnosis of $P$. malariae infections, which are rare in Korea, a molecular test would be helpful for detecting and identifying the specific species involved. In this case, the patient had a low parasite burden, and parasites were not observed in her blood films, although she was symptomatic and had not undergone prophylactic therapy with antimalarial drugs. At the time of emergence of parasites in the peripheral blood, from the low parasite burden, travel history, and incubation time, we could expect the presence of a species uncommon to our domestic area. However, the precise diagnosis at the species level was made with the aid of molecular tests.

Relatively few studies have investigated the treatment of $P$. malariae malaria compared with the treatment of $P$. falciparum malaria. Chloroquine is the first-line drug for $P$. malariae infections as well as for $P$. vivax and $P$. ovale. In general, $P$. malariae is known to be susceptible to chloroquine and to other treatments, including amodiaquine, mefloquine, and artemisinin [14]. It is very unusual for $P$. malariae to be resistant to chloroquine; however, a study has reported cases of persistent parasitemia 28 days after the initial disease management, suggesting either new infection or late recrudescence of a chloroquine-resistant strain [18]. The parasites in this case, although showing negative conversion in PBS immediately after the initiation of therapy, did not respond to chloroquine. Instead, they responded to mefloquine after a positive PCR result at the 1-month follow-up. Considering that $P$. malariae malaria is very rare in Korea, we could exclude the possibility of a new infection occurring in our patient, and late recrudescence of a chloroquine-resistant $P$. malariae strain was strongly suggested.

In summary, an imported $P$. malariae infection showing late recrudescence of a chloroquine-resistant strain was confirmed by species-specific conventional and real-time PCR assays for $18 S$ rRNA. Due to difficulties in the diagnosis of the rare Plasmodium species in Korea, molecular tests combined with morphologic examination of the PBS would help to correctly diagnose and identify the parasites and would result in better clinical management of $P$. malariae infections. 


\section{Authors' Disclosures of Potential Conflicts of Interest}

No potential conflict of interest relevant to this article was reported.

\section{REFERENCES}

1. Garcia LS. Malaria. Clin Lab Med 2010;30:93-129.

2. Breman JG. The ears of the hippopotamus: manifestations, determinants, and estimates of the malaria burden. Am J Trop Med Hyg 2001; 64(S1-2):1-11.

3. Korea Centers for Disease Control and Prevention. http://www.cdc.go.kr/ kcdchome/jsp/diseasedic/dic/DISEDIC0001Detail.jsp?menuid=510264\& contentid=8422\&boardid=null\&appid=kcdcdz01\&pageNum=null\&sub= null\&tabinx=1\&q_had01=A\&q_had02=2011\&idxType=0\&idxNum=5 (last visited on Jan 2012).

4. Whang CH. Induced malaria in Korea. Yonsei Med J 1963;4:51-7.

5. Kweon SH, Kim YS, Pai H, Park J, Park H, Choi MH, et al. A case of mixed infection with malaria and Babesia. Korean J Infect Dis 1998;30: 198-202.

6. Snounou G, Viriyakosol S, Zhu XP, Jarra W, Pinheiro L, do Rosario VE, et al. High sensitivity of detection of human malaria parasites by the use of nested polymerase chain reaction. Mol Biochem Parasitol 1993;61: 315-20.

7. Ndao M, Bandyayera E, Kokoskin E, Gyorkos TW, MacLean JD, Ward BJ. Comparison of blood smear, antigen detection, and nested-PCR methods for screening refugees from regions where malaria is endemic after a malaria outbreak in Quebec, Canada. J Clin Microbiol 2004;42:
2694-700.

8. Cnops L, Jacobs J, Van Esbroeck M. Validation of a four-primer realtime PCR as a diagnostic tool for single and mixed Plasmodium infections. Clin Microbiol Infect 2011;17:1101-7.

9. Singh B, Kim Sung L, Matusop A, Radhakrishnan A, Shamsul SS, CoxSingh J, et al. A large focus of naturally acquired Plasmodium knowlesi infections in human beings. Lancet 2004;363:1017-24.

10. Feachem RG, Phillips AA, Hwang J, Cotter C, Wielgosz B, Greenwood $\mathrm{BM}$, et al. Shrinking the malaria map: progress and prospects. Lancet 2010;376:1566-78.

11. Nzeyimana I, Henry MC, Dossou-Yovo J, Doannio JM, Diawara L, Carnevale P. The epidemiology of malaria in the southwestern forests of the Ivory Coast (Tai region). Bull Soc Pathol Exot 2002;95:89-94.

12. World Health Organization. World malaria report 2010. Available at: http: //www.who.int/malaria/world_malaria_report_2010/en/index.html (Updated in 2012).

13. Warrell DA and Gilles HM, eds. Essential malariology. 4th ed. New York: Oxford University Press, 2002:192.

14. WHO, Guidelines for the treatment of malaria, 2nd ed. Geneva: WHO, 2010.

15. Collins WE and Jeffery GM. Plasmodium malariae: parasite and disease. Clin Microbiol Rev 2007;20:579-92.

16. Kawamoto F, Liu Q, Ferreira MU, Tantular IS. How prevalent are Plasmodium ovale and P. malariae in East Asia? Parasitol Today 1999;15: 422-6.

17. Sulistyaningsih E, Fitri LE, Löscher T, Berens-Riha N. Diagnostic difficulties with Plasmodium knowlesi infection in humans. Emerg Infect Dis 2010;16:1033-4.

18. Maguire JD, Sumawinata IW, Masbar S, Laksana B, Prodjodipuro P, Susanti I, et al. Chloroquine-resistant Plasmodium malariae in south Sumatra, Indonesia. Lancet 2002;360:58-60. 